\title{
Motility of human renal cells is disturbed by infection with pathogenic hantaviruses

\author{
Stefan Hägele ${ }^{1}$, Alexander Müller ${ }^{1}$, Christian Nusshag ${ }^{2}$, Jochen Reiser ${ }^{3}$, Martin Zeier ${ }^{1}$ and Ellen Krautkrämer ${ }^{1 *}$
}

\begin{abstract}
Background: Hemorrhagic fever with renal syndrome (HFRS) caused by pathogenic hantaviruses in Europe and Asia is often characterized by acute kidney injury (AKI) with massive proteinuria. Renal filtration depends on the integrity of epithelial and endothelial monolayers in the tubular and glomerular apparatus. Tubular and glomerular cells represent target cells of hantavirus infection. However, the detailed mechanisms of renal impairment induced by hantaviruses are not well understood.

Methods: We analyzed the cellular consequences of hantavirus infection by measuring adhesion and migration capacity of human renal cells infected with Puumala (PUUV) or Hantaan (HTNV) virus. The impact of hantaviral nucleocapsid proteins ( $\mathrm{N}$ proteins) on motility was examined by transfection of podocytes.

Results: Infection of kidney cells with hantavirus species PUUV and HTNV causes a significant reduction of migration capacity. The impaired motility depends on viral replication and transfection of podocytes with $\mathrm{N}$ protein of PUUV or HTNV reveals that the expression of $\mathrm{N}$ protein alone is sufficient to deteriorate podocyte function. The cellular effects are more pronounced for the more pathogenic HTNV than for PUUV that causes a milder form of HFRS.

Conclusions: The direct impairment of migration capacity of renal cells by hantaviral N proteins may contribute substantially to proteinuria observed in the clinical picture of hantavirus infection.
\end{abstract}

Keywords: Hantavirus, Kidney, Tubular epithelium, Glomerulus, Podocytes, Proteinuria

\section{Background}

Hantaviruses are distributed worldwide and among the emerging pathogens that attract the attention of kidney research due to increasing numbers of cases and due to identification of novel species with pathogenic potential to humans [1]. HFRS varies considerably in its symptoms and severity depending on the causative virus species. Severe infections with hantaviruses HTNV, Dobrava-Belgrade virus (DOBV), or PUUV are characterized by AKI with massive proteinuria. The proteinuria is non-selective indicating that glomerular and tubular structures are affected [2]. Moreover, immunofluorescence and electron microscopy studies demonstrate tubular and glomerular changes in renal specimens of patients with hantavirus infection [3-5].

\footnotetext{
* Correspondence: ellen.krautkraemer@med.uni-heidelberg.de

${ }^{1}$ Department of Nephrology, University of Heidelberg, Im Neuenheimer Feld

162, 69120 Heidelberg, Germany

Full list of author information is available at the end of the article
}

The glomerular filtration barrier mainly exerts its function via three layers: fenestrated endothelium, glomerular basement membrane (GBM), and podocytes. Normal kidney filter function depends on the integrity of GBM and of tubular and glomerular monolayers. Cell adhesion and individual cell motility play a pivotal role in the establishment and maintenance of cell-to-cell contacts, polarity, and renal filtration. Cytoskeletal alterations are characteristic for many renal diseases and changes in motility correlate with proteinuria [6-8]. Glomerular proteinuria is predictive for the severity of hantavirus-induced AKI [9]. The infection of renal cells by hantaviruses may contribute to proteinuria and may represent a determinant in the clinical course of HFRS. Hantaviral N protein was detected in tubular and glomerular cells and cell-to-cell contact structures were changed in biopsy samples of patients with serologically confirmed PUUV infections [3].

(c) The Author(s). 2018 Open Access This article is distributed under the terms of the Creative Commons Attribution 4.0 International License (http://creativecommons.org/licenses/by/4.0/), which permits unrestricted use, distribution, and reproduction in any medium, provided you give appropriate credit to the original author(s) and the source, provide a link to the Creative Commons license, and indicate if changes were made. The Creative Commons Public Domain Dedication waiver (http://creativecommons.org/publicdomain/zero/1.0/) applies to the data made available in this article, unless otherwise stated. 
However, the underlying mechanisms and effects of hantavirus infection on human renal cells have not been investigated so far. To identify the consequences of hantavirus infection, we analyzed adhesion and motility capacity of human renal cells infected with hantaviruses PUUV or HTNV.

\section{Methods}

\section{Cells}

Primary podocytes (Lonza) were maintained in RPMI medium (Capricorn) supplemented with $10 \%$ fetal calf serum (FCS). Human renal epithelial cells (HREpCs) (PromoCell) were cultured in renal epithelial cell growth medium-2 (PromoCell). Human renal glomerular endothelial cells (HRGEnC) (ScienCell) were maintained in endothelial cell medium ECM (ScienCell). Primary cells were only used from passage two to six. The human podocyte cell line was derived from human normal podocytes conditionally transformed with a temperature-sensitive mutant of the simian virus 40 (SV40) large T antigen. Cells were cultured as previously described [10]. Experiments were performed with non-proliferating, differentiated podocytes expressing synaptopodin as podocyte-specific marker of differentiation. Vero E6 cells were maintained in DMEM (Capricorn) supplemented with 10\% FCS.

\section{Viruses and infection}

Hantavirus species HTNV strain 76-118 and PUUV strain Vranica were propagated on Vero E6 cells. For infection, cells were incubated with viral inocula at a multiplicity of infection (MOI) of 0.5 and medium was replaced after six hours. MOI was calculated on the respective cell type. On day six after infection, infected cells were quantified by detection of $\mathrm{N}$ protein expression via immunofluorescence staining and subjected to the assays.

\section{Human sera samples}

Heat-inactivated $\left(56^{\circ} \mathrm{C}, 30 \mathrm{~min}\right)$ serum samples of three healthy volunteers and three patients with serologically confirmed PUUV infection were used for incubation of podocytes in migration assays. Semiquantitative proteinuria was determined by urine dipstick: +: $30 \mathrm{mg} / \mathrm{dL},++$ : $100 \mathrm{mg} / \mathrm{dL},+++: 300 \mathrm{mg} / \mathrm{dL}$, and ++++: $1000 \mathrm{mg} / \mathrm{dL}$. Clinical data were collected through a review of medical charts of the Department of Nephrology of the University of Heidelberg, Germany. This study was approved by the Ethics Committee of the University of Heidelberg and it adhered to the Declaration of Helsinki. Written informed consent was obtained from all participants.

\section{Immunofluorescence (IF)}

Cells grown on coverslips were fixed with $3 \%$ paraformaldehyde (PFA) and stained with primary and fluorescently-labeled secondary antibodies. The following primary antibodies were used: Mouse anti-N protein PUUV (A1C5, Progen), mouse anti-N protein HTNV (B5D9, Progen). Cell nuclei were stained by Hoechst 33342 (Invitrogen). Images were taken using an Axiocam 506 mono camera attached to an Axio Observer.D1 inverted microscope (Carl Zeiss).

\section{Western blot}

For Western blot analysis, samples were boiled in SDS sample buffer, separated by SDS-PAGE, and transferred to a nitrocellulose membrane. Membranes were blocked with 5\% nonfat dried milk in Tris-buffered saline containing $0.1 \%$ Tween20 (TBST) for $30 \mathrm{~min}$ at room temperature and then incubated for one hour at room temperature with the following antibodies: Mouse anti-N protein PUUV (A1C5, Progen), mouse anti-N protein HTNV (B5D9, Progen). After washing with TBST, the membrane was incubated with near-infrared fluorescently-labeled anti-mouse secondary antibodies (IRDye800, Li-Cor) for one hour at room temperature. After washing with TBST, the membrane was scanned by the Odyssey CLx infrared imaging system (Li-Cor).

\section{Treatment of viral supernatants}

Infectious hantaviral particles in supernatants derived from infected podocytes on day six after infection were inactivated by UV irradiation $\left(1.4 \mathrm{~J} / \mathrm{cm}^{2}\right)$ with Stratalinker UV Crosslinker equipped with $254 \mathrm{~nm}$ UV-light bulbs or depleted by filtration at $5000 \mathrm{~g}$ at $4{ }^{\circ} \mathrm{C}$ for $2 \mathrm{~h}$ through Nanosep centrifugal device with Omega membrane $300 \mathrm{~K}$ (Pall Life Sciences) with a molecular weight cut-off of 300 $\mathrm{kDa}[11]$.

\section{Transfection of cells}

Podocytes were transfected with pmaxGFP encoding green fluorescent protein (Lonza) together with pCR3.1 (Invitrogen) encoding full-length $\mathrm{N}$ protein of PUUV or HTNV using nucleofection (Amaxa Nucleofector 2b device, Lonza) with the Basic Nucleofector Kit for primary mammalian epithelial cells (Lonza). Transfection of pmaxGFP together with empty vector (mock) served as control. After eight hours, cells were subjected to live cell imaging or immunofluorescence. All cells expressing maxGFP co-expressed hantaviral $\mathrm{N}$ protein. Percentage and viability of cells expressing max GFP together with $\mathrm{N}$ protein did not differ compared to cells transfected with pmaxGFP and empty vector. Amount of $\mathrm{N}$ protein expression was quantified by determination of the fluorescence levels of 100 transfected cells that were stained for $\mathrm{N}$ protein with anti- $\mathrm{N}$ protein antibody. Area, mean fluorescence signal, and adjacent background readings were measured for each cell using ImageJ (v1.52e, NIH). The fluorescence levels were calculated with ImageJ as 
total corrected cell fluorescence (TCCF) of $\mathrm{N}$ protein $(\mathrm{TCCF}=$ integrated density $-($ area of selected cell $\times$ mean background fluorescence)) [12].

\section{Viability assay}

Uninfected and infected cells were lysed on day six after infection. The number of viable cells was determined by measuring the amount of ATP using CellTiter-Glo luminescent cell viability assay (Promega).

\section{Live cell imaging and single cell tracking}

Infected and transfected cells $\left(10,000\right.$ cells $\left./ \mathrm{cm}^{2}\right)$ on $\mu$-slide 2-wells (Ibidi) were subjected to live cell imaging. The motility of infected and uninfected podocytes was monitored for eight hours by JuLi Smart Fluorescence Cell Imager (Digital-Bio). Cells were tracked by the ImageJ manual tracking plugin (Ibidi) and statistical analysis was done by using the chemotaxis tool plugin
(Ibidi). The migration of podocytes co-transfected with $\mathrm{N}$ protein together with green fluorescent protein (maxGFP; Lonza) was recorded using a Ti-HCS microscope with an Andor Clara interline-CCD-camera (Nikon). Cells expressing maxGFP were tracked and analyzed as described for infected cells.

\section{Migration assay}

Podocytes $\left(45,000\right.$ cells $\left./ \mathrm{cm}^{2}\right)$ were seeded into $\mu$-plate wells (Ibidi) and infected with hantaviruses. The insert was removed six days after infection and images were taken immediately after insert removal and after eight hours by JuLi Smart Fluorescence Cell Imager (Digital Bio). The average area of migrated cells was measured in three independent experiments. Cells were fixed with 3\% PFA and stained for nuclei and hantaviral $\mathrm{N}$ protein.

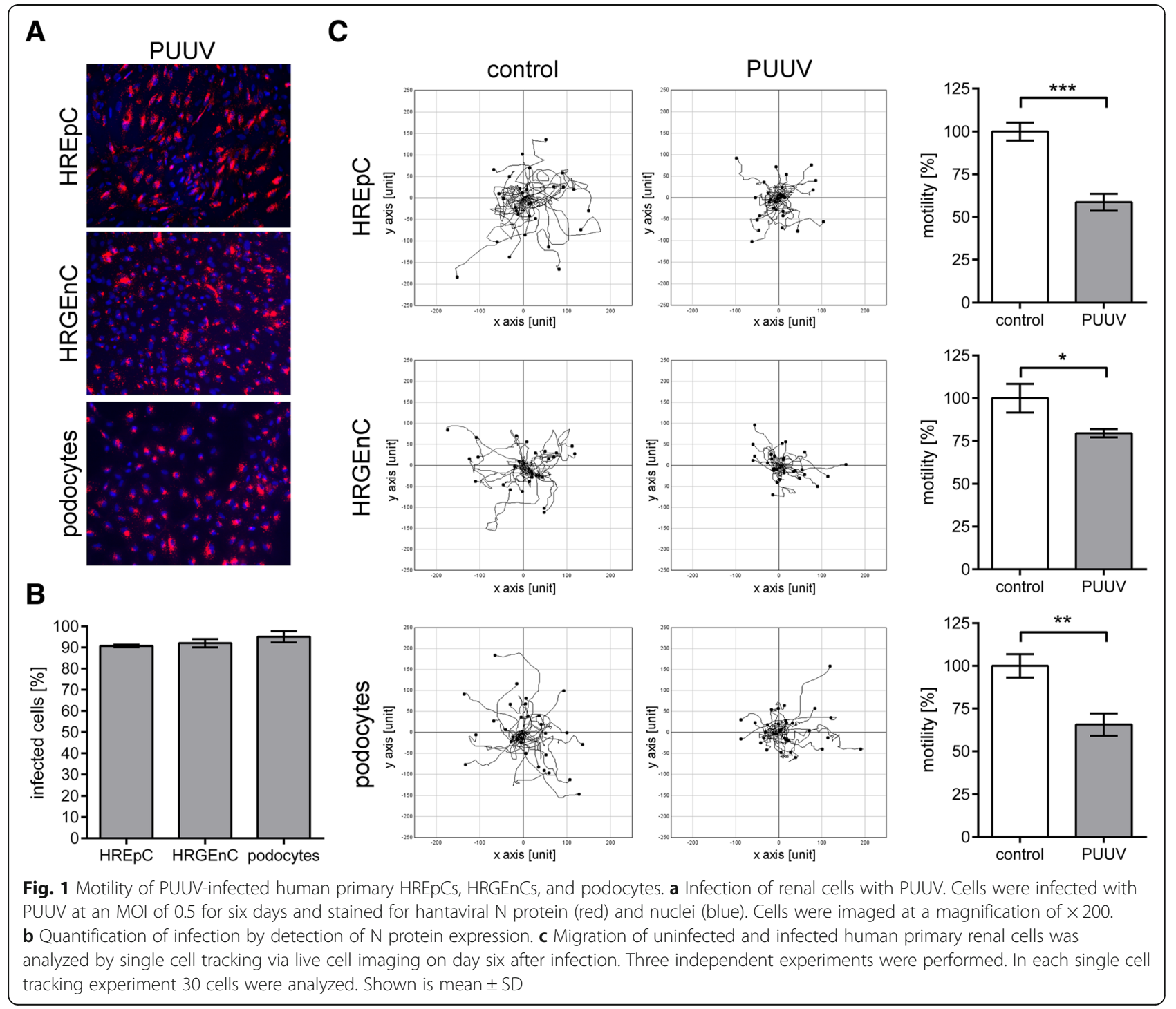




\section{Adhesion assay}

Uninfected or infected podocytes of a single-cell suspension $\left(29,000\right.$ cells $\left./ \mathrm{cm}^{2}\right)$ were added in each well of a 96-well microtiter plate and left to adhere for one hour at $37^{\circ} \mathrm{C}$. After a triple wash with PBS, adhered cells were fixed, and stained with Sapphire700 (Li-Cor) and DRAQ5 (BioStatus) and quantified via scanning with Odyssey CLx infrared imaging system (Li-Cor).

\section{Statistical analysis}

Data were analyzed using Prism 5.0 (GraphPad Software Inc.). Normal distribution was tested with the Kolmogorov-Smirnov test. Values of two groups were compared using two-tailed Student's t-test. Values were presented as mean \pm standard deviation (SD). $P$ values of $\leq 0.05$ were considered significant. ${ }^{*} P \leq 0.05 ;{ }^{* *} P \leq 0.01$; **** $P \leq 0.001 ;{ }^{* * * * *} P \leq 0.0001 ;$ ns: not significant.

\section{Results}

Migration capacity of PUUV-infected human primary renal cells

To analyze if hantavirus infection interferes with renal cell function, we measured the motility of PUUV-infected primary HREpCs, HRGEnCs, and human primary podocytes by single cell tracking. Infection was monitored by immunostaining for $\mathrm{N}$ protein revealing that more than $90 \%$ of cells were positive for PUUV $\mathrm{N}$ protein (Fig. 1a and b). Infection of human primary tubular (HREpCs) and glomerular (HRGEnCs and podocytes) cells resulted in an impaired migration capacity as revealed by single cell tracking (Fig. 1c). Motility of infected tubular epithelial cells was reduced to $58.65 \% \pm 2.87 \%$ compared to uninfected HREpCs $(100 \% \pm 3.05 \% ; P=$ 0.0006). In glomerular cells the levels were reduced to $79.48 \% \pm 1.43 \%$ vs. $100 \% \pm 4.86 \% ; P=0.0154$ and to

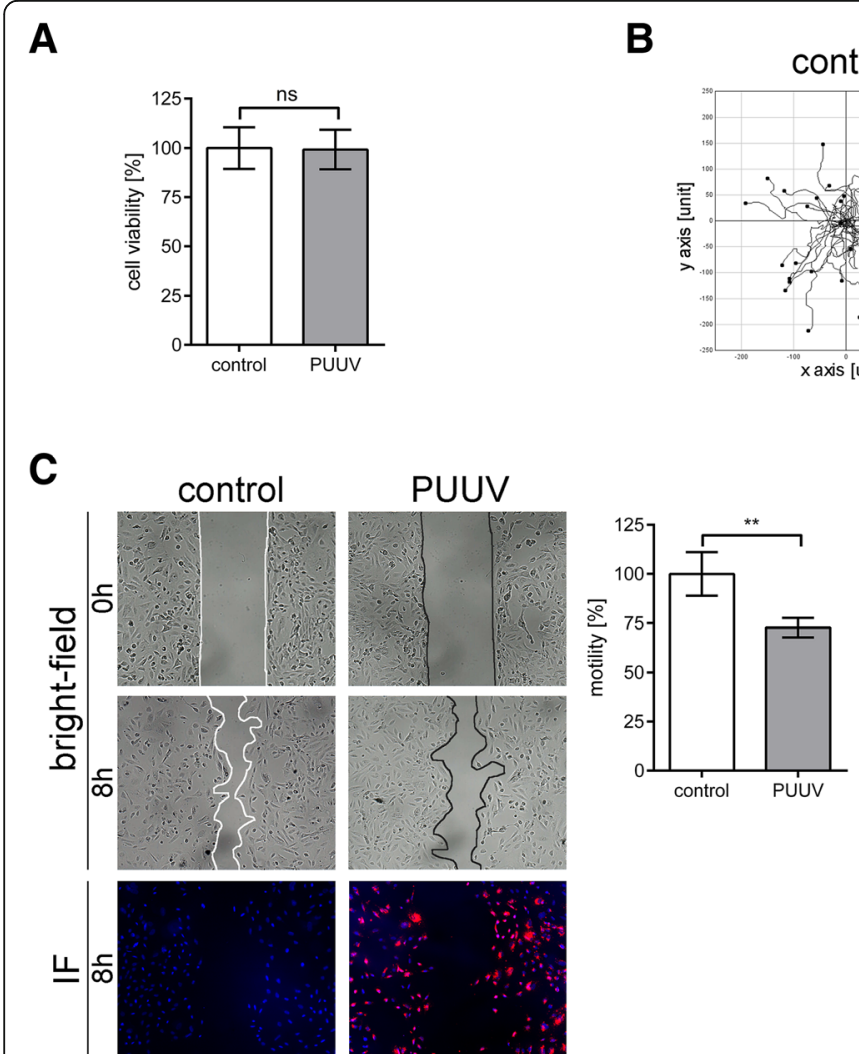

D

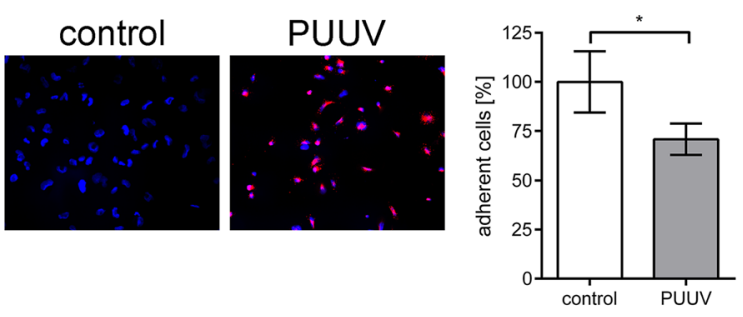

Fig. 2 Functional consequences of PUUV-infection in human podocytes. a Podocytes were infected with PUUV at an MOI of 0.5 and viability was assessed on day six post infection. Control cells remained uninfected and viability was set to $100 \%$. Three independent experiments were performed in triplicates. Shown is mean \pm SD. $\mathbf{b}$ Migration of uninfected and infected podocytes was analyzed by single cell tracking via live cell imaging. Three independent experiments were performed. In each experiment 30 cells were analyzed. Shown is mean \pm SD. c For migration assay, podocytes were seeded into $\mu$-plate wells and infected with PUUV at an $\mathrm{MOI}$ of 0.5 for six days. After removal of the insert and after eight hours, cell-free areas were measured and relative migration was calculated. Migration of uninfected podocytes was set to $100 \%$. Representative images are shown. Nuclei were stained in blue, $\mathrm{N}$ protein in red. Cells were imaged at a magnification of $\times 100$. Three independent experiments were performed. Shown is mean \pm SD. d Adhesion of PUUV-infected cells. Uninfected and PUUV-infected podocytes were plated into 96 wells and numbers of attached cells were quantified after one hour. Nuclei were stained in blue, $\mathrm{N}$ protein in red. Cells were imaged at a magnification of $\times 200$. Adhesion of uninfected cells was set to $100 \%$. Results were obtained from three independent experiments, each performed in quadruplicate. Shown is mean \pm SD 
$65.66 \% \pm 3.76 \% \quad$ vs. $100 \% \pm 3.97 \% ; \quad P=0.0033$ for HRGEnCs and podocytes, respectively.

\section{Migration and adhesion capacity of PUUV- infected podocytes}

Using a human podocyte cell line, we studied the functional consequences of hantavirus infection of renal cells in more detail. We tested the viability of podocytes after infection with PUUV (Fig. 2a). Quantification of infected cells by immunofluorescence of $\mathrm{N}$ protein revealed that $93.19 \% \pm 2.29 \%$ of cells were infected with PUUV. The infection had no effect on viability. Motility was also analyzed for the PUUV-infected podocyte cell line (Figs $2 \mathrm{~b}$ and $\mathrm{c}$ ). The distance covered by infected podocytes was reduced to $73.35 \% \pm 4.24 \%$ compared to uninfected cells $(100 \% \pm 3.06 \% ; P=0.0003)$. Measuring cell-free areas by migration assays revealed a migration capacity of infected monolayers that was reduced to $72.80 \% \pm 4.89 \%$ vs. $100 \% \pm 11.06 \%$; $P=$ 0.0041 . In addition, we examined the adhesion of infected cells (Fig. 2d). After infection, the number of adherent cells was decreased to $70.96 \% \pm 7.88 \%$ vs. $100 \% \pm 15.53 \% ; P=0.0446$.

\section{Migration and adhesion capacity of HTNV- infected podocytes}

To investigate whether the effects on podocytes are related to other pathogenic Old World hantaviruses, we examined the infection of podocytes with HTNV (Fig. 3). Quantification of infected cells by immunofluorescence of $\mathrm{N}$ protein revealed that $91.76 \% \pm 1.37 \%$ of cells were infected with HTNV. Viability of podocytes was not influenced by HTNV infection (Fig. 3a). Motility was impaired compared to uninfected
A

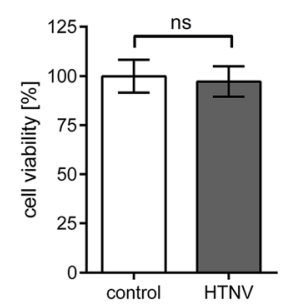

B

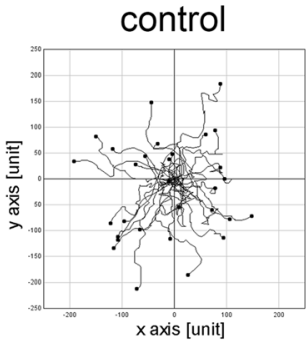

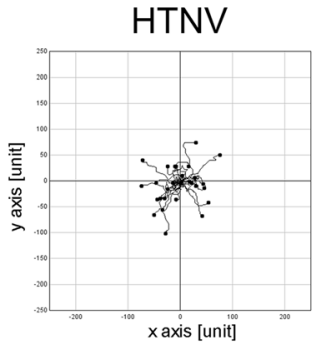

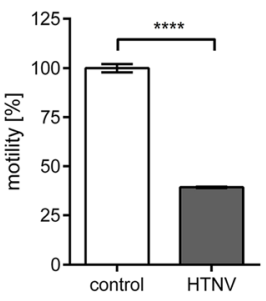

C

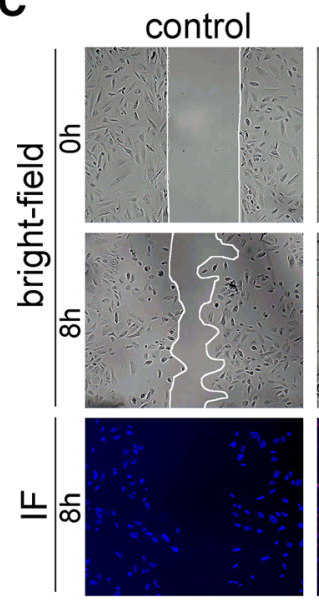

HTNV

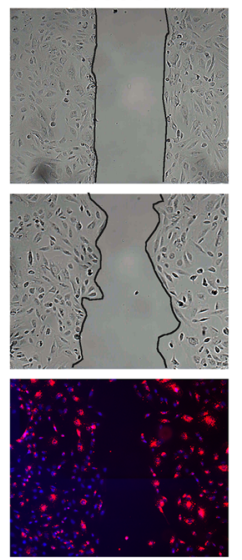

D
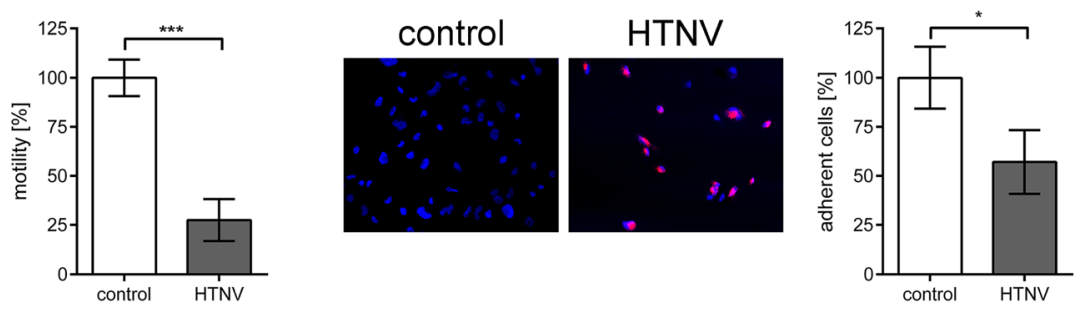

Fig. 3 Functional consequences of HTNV-infection in human podocytes. a Podocytes were infected with HTNV at an MOI of 0.5 and viability was assessed on day six post infection. Control cells remained uninfected and viability was set to $100 \%$. Three independent experiments were performed in triplicates. Shown is mean \pm SD. $\mathbf{b}$ Motility of uninfected and infected podocytes was analyzed by single cell tracking via live cell imaging. Three independent experiments were performed. In each experiment 30 cells were analyzed. Shown is mean \pm SD. c Podocytes seeded into $\mu$-plate wells were infected with HTNV and analyzed by migration assay after six days after infection. After removal of the insert and after eight hours, cell-free areas were measured and relative migration was calculated. Migration of uninfected podocytes was set to $100 \%$.

Representative images are shown. Cells were imaged at a magnification of $\times 100$. Three independent experiments were performed. Shown is mean \pm SD. d Uninfected and HTNV-infected cells were plated into 96 wells and numbers of attached cells were quantified after one hour. Results were obtained from three independent experiments, each performed in quadruplicate. $N$ protein was stained in red. Cells were imaged at a magnification of $\times 200$. Adhesion of uninfected cells was set to $100 \%$. Shown is mean \pm SD 
podocytes (Fig. 3b and c). The distance covered by HTNV-infected podocytes was reduced to $40.02 \% \pm$ $1.92 \%$ vs. $100 \% \pm 2.21 \% ; P<0.0001$ and migration of infected monolayers was decreased to $27.49 \% \pm 10.69 \%$ vs. $100 \% \pm 9.29 \% ; P=0.0009$. Adhesion capacity was also reduced in HTNV-infected podocytes $(57.13 \% \pm$ $16.28 \%$ vs. $100 \% \pm 15.7 \% ; P=0.0304$ ) (Fig. $3 \mathrm{~d}$ ). The HTNV-mediated deterioration of podocyte functions was more pronounced than the effects caused by PUUV infection.

\section{Migration of podocytes incubated with culture} supernatants and sera

Next, we examined whether viral replication is required for the impairment of migration (Fig. 4). To inactivate or deplete infectious PUUV and HTNV particles, supernatants were UV-treated or filtrated. Inactivation and removal of infectious particles were controlled by Western blot analysis of $\mathrm{N}$ protein and by inoculation of Vero E6 cells (Fig. 4a and c). N protein was no longer detected in the filtrates and no infection was observed in Vero E6

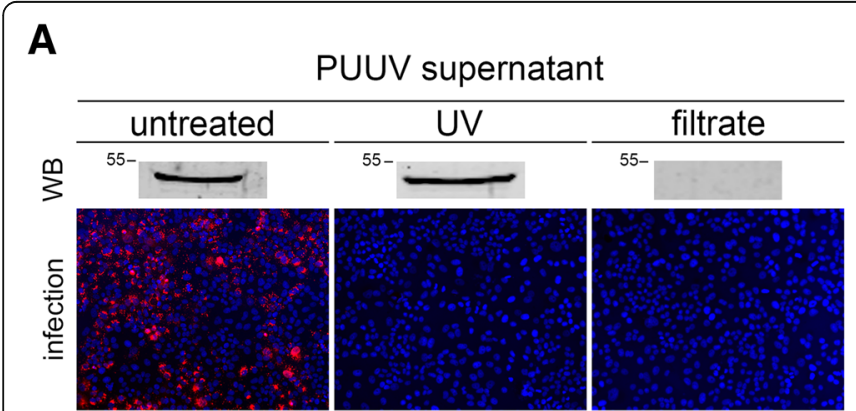

B

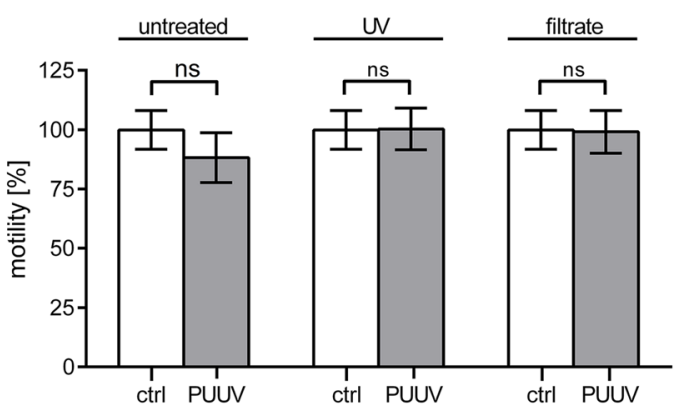

C

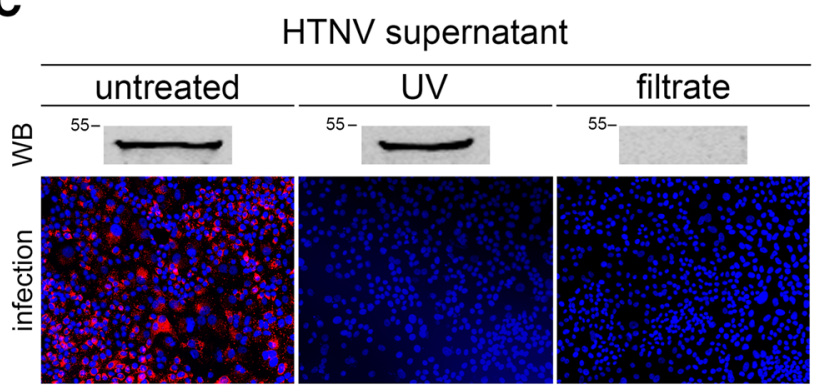

D

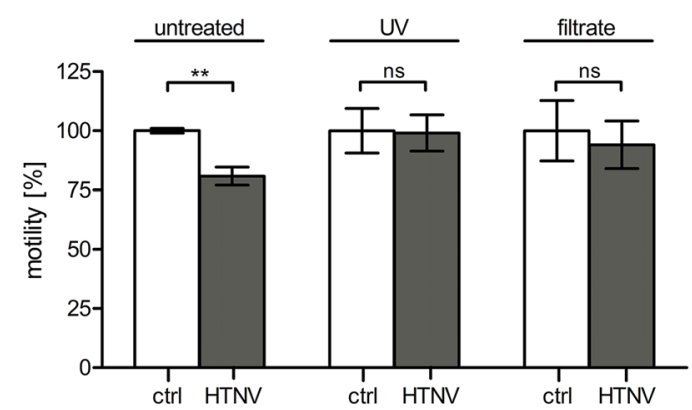

$\mathbf{E}$

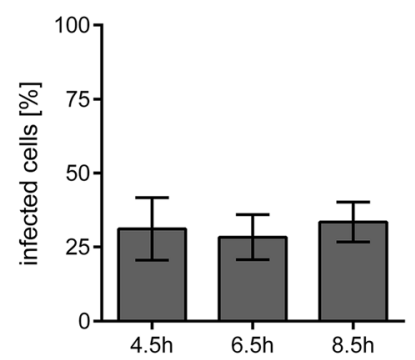

$\mathbf{F}$

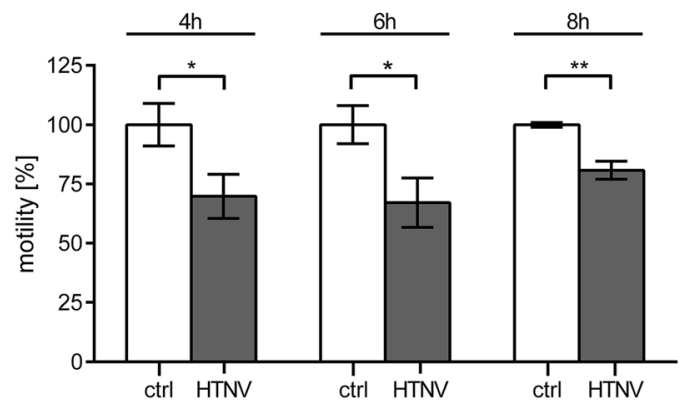

Fig. 4 Motility of podocytes incubated with supernatants of infected podocytes. a Untreated, UV-irradiated, and filtrated supernatants of podocytes infected with PUUV for six days at an $\mathrm{MOI}$ of 0.5 were analyzed for the presence of $\mathrm{N}$ protein by Western blot and for infectivity via incubation of Vero E6 cells and subsequent detection of N protein (red). Cells were imaged at a magnification of $\times 200$. $\mathbf{b}$ Supernatants and filtrates were added to uninfected podocytes 30 min before migration assay. Migration assay was performed in the presence of supernatants and filtrates and analyzed as described in Fig. 2c. Migration of podocytes in the presence of untreated, UV-irradiated, and filtrated supernatants of uninfected podocytes served as control (ctrl) and was set to 100\%. (c and d) Supernatants of HTNV-infected podocytes were treated and analyzed as described for PUUV in (a and (b). (e and $\mathbf{f}$ ) Time course of infection and motility analyzed in podocytes inoculated with untreated supernatants derived from HTNV-infected podocytes after six days of infection. e Infection was quantified by counting cells expressing $\mathrm{N}$ protein at the indicated time points. $\mathbf{f}$ Migration assays were started after $30 \mathrm{~min}$ of incubation with supernatant and motility was analyzed at the indicated time points. Untreated supernatants of uninfected podocytes served as control (ctrl) and was set to 100\%. Results were obtained from three independent experiments. Shown is mean \pm SD 
cells incubated with UV-irradiated or filtrated supernatants. Migration assays with podocytes inoculated with supernatants derived from HTNV-infected podocytes revealed that migration capacity is reduced in the presence of infectious particles. In contrast, incubation with supernatants containing UV-inactivated particles or with filtrated supernatants did not change the migration of uninfected podocytes. No significant effect was observed in samples inoculated with supernatant derived from PUUV-infected podocytes (Fig. 4b and d). Quantification of infection in podocytes incubated with untreated supernatants by detection of $\mathrm{N}$ protein after migration assay, revealed that $33.48 \% \pm 6.74 \%$ of cells were infected with HTNV and $4.51 \% \pm 3.72 \%$ with PUUV after $8.5 \mathrm{~h}$ of incubation. The high percentage of HTNV-infected cells may account for the decrease in motility. Therefore, the hantavirus-mediated impairment of podocyte migration depends on viral replication. We examined the levels of infection and decrease of motility at earlier time points after incubation with untreated supernatants collected from HTNV-infected podocytes. $30.20 \% \pm 9.31 \%$ of cells were infected at $4.5 \mathrm{~h}$ after adding supernatants and the motility was decreased to $69.81 \% \pm 9.32 \%$ (Fig. $4 \mathrm{e}$ and f). Levels of infected cells and motility impairment did not change over time. The effect is observed very early after infection and does not depend on viral spread.

We analyzed whether circulating factors affecting podocyte function were present in the serum of patients with acute PUUV hantavirus infection (Table 1, Fig. 5). The patients showed characteristic clinical symptoms (sudden onset of flu-like symptoms), impairment of laboratory parameters (thrombocytopenia, rise in levels of serum creatinine, leukocytes, LDH, CRP, and low levels of serum albumin), proteinuria, and hematuria. Sera samples of the three patients were collected during the clinical course and subjected to migration assays with uninfected podocytes in vitro. Figure 5 shows the course of serum creatinine levels of patients and the migration capacity of podocytes incubated with sera collected at the indicated time points. None of the seven sera sampled at different phases of the clinical course of the three patients demonstrated any impact on the migration of podocytes compared to sera of healthy control individuals or normal cell culture medium. Podocytes incubated with sera from infected patients were not infected as revealed by immunofluorescence analysis of $\mathrm{N}$ protein expression (data not shown).

\section{Functional consequences of hantaviral $\mathrm{N}$ protein expression}

The multifunctional hantaviral $\mathrm{N}$ protein is the most abundant protein early in infection [13]. Therefore, we wanted to investigate if the expression of $\mathrm{N}$ protein is sufficient to induce impairment of podocyte function. We performed single cell tracking of $\mathrm{N}$ protein-transfected podocytes by live cell microscopy (Fig. 6). The motility analysis of podocytes expressing recombinant $\mathrm{N}$ proteins revealed a reduction of the covered distance to $46.92 \% \pm 8.85 \% ; P=0.0017$ for HTNV and to $72.90 \% \pm$ 7.22\%; $P=0.0134$ for PUUV compared to mock-transfected cells $(100 \% \pm 8.45 \%)$ (Fig. 6a). Despite equal expression levels of HTNV and PUUV N protein as revealed by determination of fluorescence intensity (Fig. 6b), the effect on podocyte motility was less pronounced for PUUV $\mathrm{N}$ protein. Interestingly, the transfection of $\mathrm{N}$ protein results in a reduction of motility capacity that is exactly the same level as observed in infection with the respective virus species (Figs. 2b, 3b): the motility of podocytes infected with HTNV was reduced to $40.02 \% \pm 1.92 \%$ and motility of podocytes transfected with HTNV N protein was decreased to $46.92 \% \pm 8.85 \% \quad(P=0.2092)$. Podocytes infected with PUUV exhibited a reduced motility of $73.35 \% \pm 4.24 \%$ and motility of podocytes expressing PUUV $\mathrm{N}$ protein was reduced to $72.90 \% \pm 7.22 \%(P=0.7876)$.

Table 1 Characteristics and laboratory parameters of three patients with acute PUUV HFRS ${ }^{a}$

\begin{tabular}{|c|c|c|c|c|}
\hline & $\# 64$ & $\# 176$ & \#211 & Reference \\
\hline Age (years) & 37 & 53 & 25 & \\
\hline Gender & $\mathrm{m}$ & $\mathrm{m}$ & $\mathrm{m}$ & \\
\hline Duration of hospitalization (days) & 8 & 15 & 10 & \\
\hline Max serum creatinine level $(\mathrm{mg} / \mathrm{dL})$ & $11.94(9)$ & $12.16(10)$ & $10.89(7)$ & $0.1-1.3$ \\
\hline Min serum albumin level (g/L) & $28(3)$ & $31(7)$ & $31.1(8)$ & $30-50$ \\
\hline Max leukocyte count $\left(10^{9} / \mathrm{L}\right)$ & $15.6(3)$ & $15.73(5)$ & $7.57(4)$ & $4-10$ \\
\hline Min platelet count $\left(10^{9} / \mathrm{L}\right)$ & $65(2)$ & $52(3)$ & $49(3)$ & $150-440$ \\
\hline Max LDH activity (U/L) & $329(8)$ & $405(8)$ & $422(4)$ & $<248$ \\
\hline Max CRP level (mg/L) & $94.5(2)$ & $143.7(3)$ & $61.2(4)$ & $<5$ \\
\hline Urine dipstick protein & $+++(2)$ & $+++(7)$ & $++++(4)$ & - \\
\hline Urinary erythrocyte count $(/ \mu \mathrm{L})$ & $25(3)$ & $69(3)$ & $43(5)$ & 0 \\
\hline
\end{tabular}

anumbers in brackets indicate the days post onset 

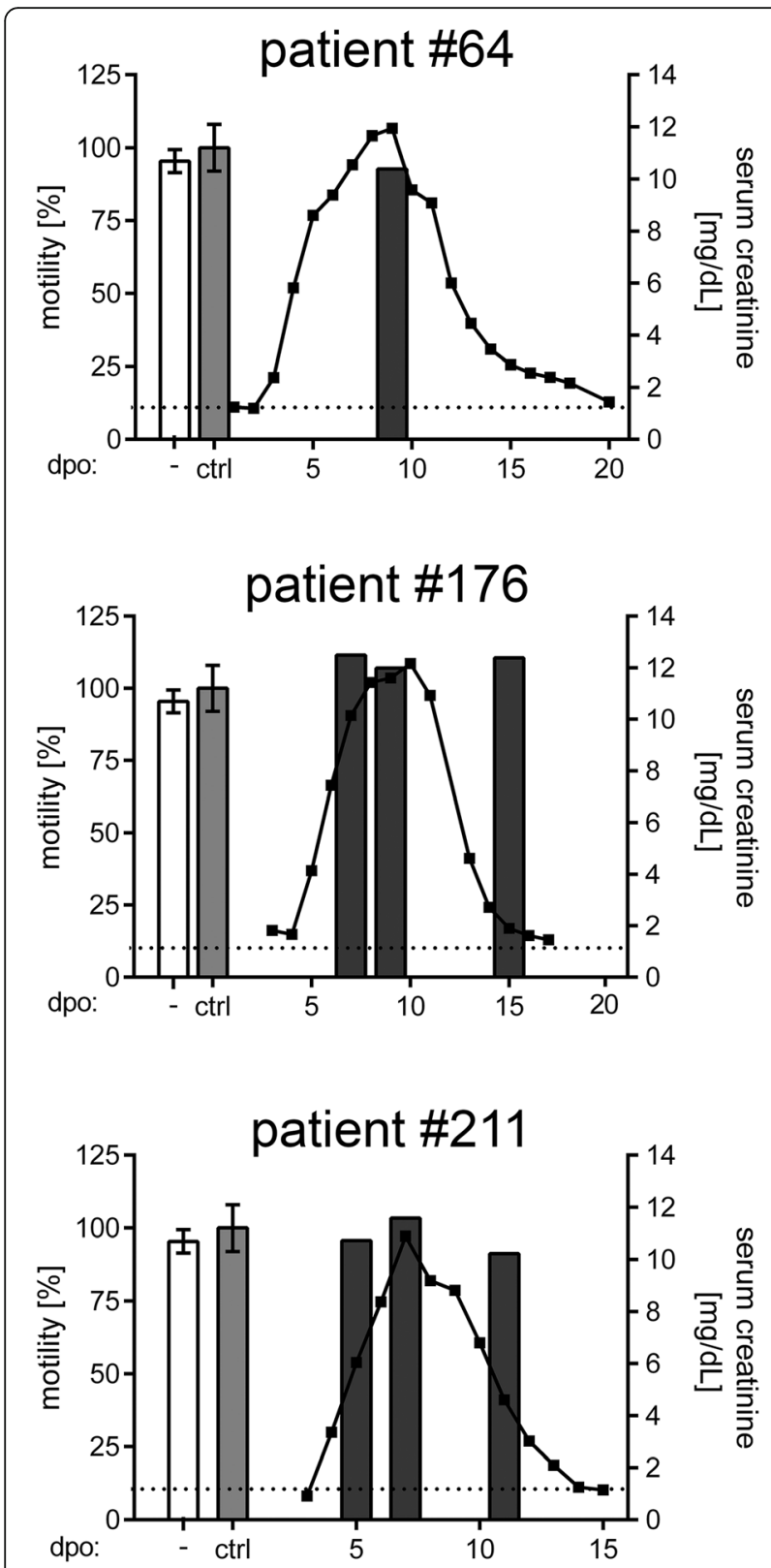

Fig. 5 Migration of podocytes inoculated with sera of patients with PUUV infection. Podocytes were inoculated with normal podocyte medium containing $10 \%$ FCS (-, white bars), medium containing $50 \%$ serum of healthy control individuals (ctrl, light grey bars), or with medium containing 50\% serum of patients with PUUV infection collected during the clinical course (dark grey bars) and analyzed by migration assay. Sera were added 30 min before insert removal. Averaged migration of podocytes in the presence of sera derived from three healthy donors was set to $100 \%$. Shown is mean \pm SD Levels of patients' serum creatinine were shown on the right $y$-axis to monitor the clinical course of infection. Dashed horizontal line indicates the reference value of serum creatinine for healthy individuals. Dpo: days post onset
Together, these results demonstrate that the expression of hantaviral $\mathrm{N}$ proteins alone is sufficient to induce impairment of podocyte motility in a virus-specific manner.

\section{Discussion}

Damage to host organisms by pathogens may indirectly occur via the immune system and/or directly due to interference with cellular processes during their replication cycle. The direct effects are often cell type-specific and mediated by modulation of structural components or interference with signaling pathways of the host cell. Hantaviruses infect different organs and cell types. Cells of the respiratory tract, of the kidney, and of the immune system have been described to be susceptible to hantavirus infection [3, 14-17]. In most cases of infections with Old World hantaviruses, renal involvement dominates and leads to AKI, proteinuria, and microhematuria. The underlying molecular and cellular mechanisms in the pathogenesis of AKI and leakage are not completely understood. Direct effects observed in infected renal cells such as disruption of cell-to-cell contacts and alterations in motility and adhesion contribute to proteinuria. However, the role of direct infection of target cells in the failure of organs in HCPS and HFRS needs to be further investigated.

We demonstrate that hantaviruses disturb cellular function of human primary renal cells that may result in proteinuria. Infection of both, tubular and glomerular cell types, leads to severe alterations in motility. The expression of hantaviral $\mathrm{N}$ protein alone is sufficient to impair migration. $\mathrm{N}$ protein may represent a pathogenicity factor of hantavirus-induced proteinuria. An association of structural changes and hantaviral $\mathrm{N}$ protein expression has also been described in tubules of patients with acute hantavirus infection [3].

Neither non-infectious supernatants derived from infected podocytes nor sera from patients with hantavirus infection exhibit any effect on podocytes in vitro. Therefore, viral replication is required to impair cellular motility. In addition, local effects of soluble factors released by renal or immune cells may contribute to the clinical course in vivo. It is also possible that infection sensitizes renal cells to soluble factors, as it is described for hantavirus-infected HUVECs and VEGF [18]. Cytokines may act on these cells and contribute or counteract to motility alterations. Several signal cascades have been described to be involved in the regulation of podocyte function: vascular endothelial growth factor (VEGF), urokinase plasminogen activator receptor (UPAR), or interleukin-6 (IL-6) are modulators of podocyte signaling $[7,19,20]$. Interestingly, these mediators are also known to be up-regulated in hantavirus infection [21-24]. In cells sensitized by infection, these effectors may 


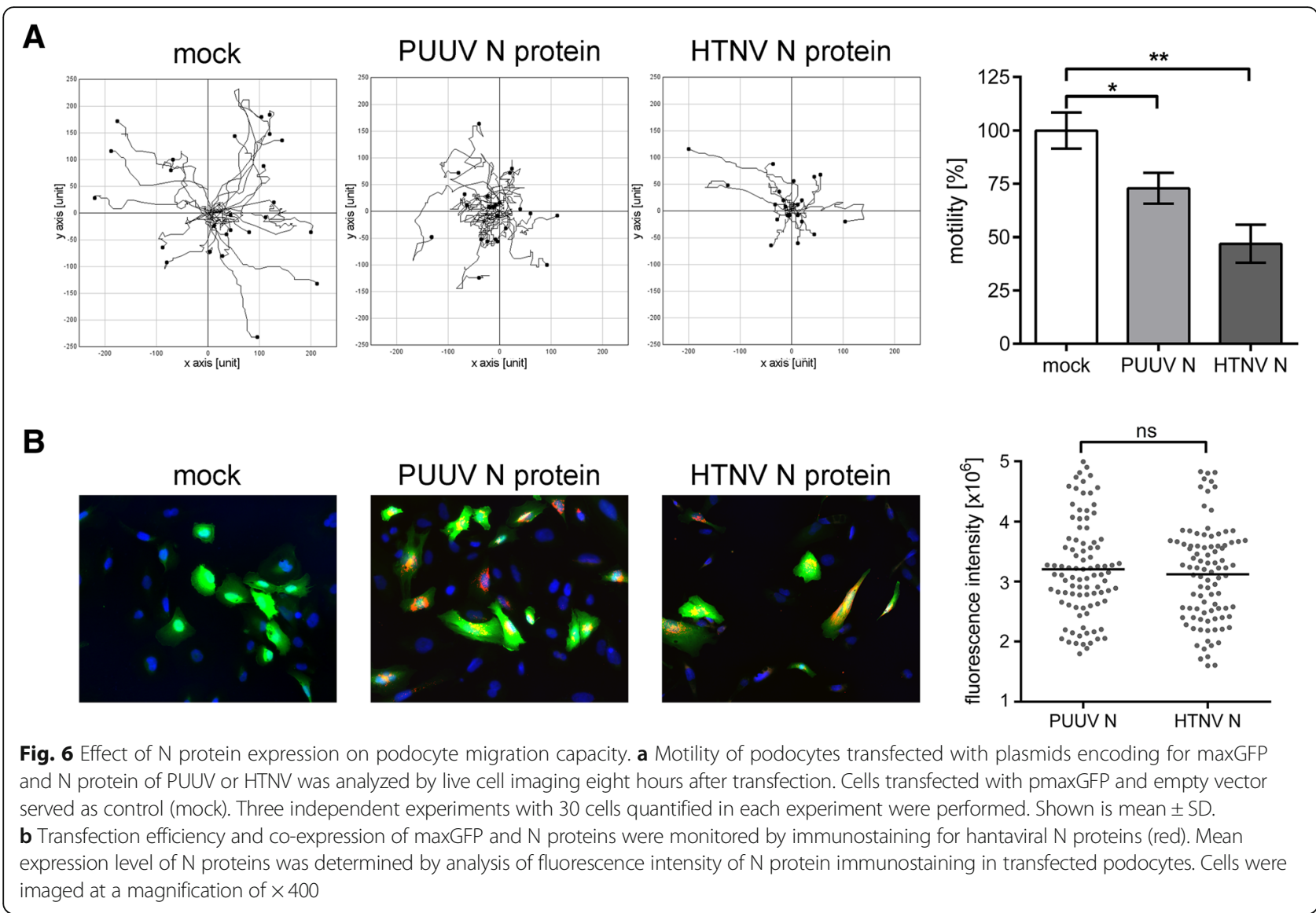

contribute or counteract to the impairment of motility mediated by $\mathrm{N}$ protein expression. Further studies are necessary to resolve the role of direct and indirect effects of hantavirus infection in the balance of podocyte motility and transient proteinuria.

The functional consequences of infection and $\mathrm{N}$ protein expression were more pronounced for HTNV than for PUUV. These observations from in vitro experiments correspond to the clinical picture of PUUV- and HTNV-induced HFRS with HTNV being the more pathogenic virus species [25]. However, it remains to examine if the observed cellular effects of renal infection contribute to the severity of the clinical course of PUUV and HTNV infection. The underlying mechanisms for differences in hantaviral pathogenicity are not fully understood. Analysis of reassortants between the weakly pathogenic DOBV-Aa subtype and the highly virulent subtype DOBV-Af revealed that characteristics concerning induction of the innate immune system in host cells are determined by the segments encoding for $\mathrm{N}$ protein and RNA-dependent RNA polymerase [26]. Studies with New World hantavirus Andes virus (ANDV) indicated that the $\mathrm{N}$ protein of ANDV interferes with signaling cascades of the innate immune system $[27,28]$. Gorbunova et al. demonstrated that the ANDV N protein enhances permeability of microvascular endothelial cells via activation of RhoA [29]. These findings and our results show that $\mathrm{N}$ proteins of New and Old World hantaviruses interfere with cellular signaling and function and may act as a pathogenicity factor in hantavirus infection.

Hantaviral $\mathrm{N}$ proteins share high homology between species and it would be of great interest to identify $\mathrm{N}$ protein-specific characteristics responsible for the differences in the functional outcome. Future work will focus on the mode of interaction of different hantaviral $\mathrm{N}$ proteins with specific target cells. The analysis of the underlying mechanisms of $\mathrm{N}$ protein-induced cellular alterations will help to understand the pathogenesis of renal impairment caused by hantavirus infection.

\section{Conclusions}

Acute kidney injury with massive proteinuria is a hallmark of HFRS. The mechanisms of renal impairment are not completely understood. Hantaviruses PUUV and HTNV infect cells of the glomerular and tubular apparatus. We showed that infection of renal cells results in severe changes in the motility capacity. 
Furthermore, our results demonstrate an important role of hantaviral $\mathrm{N}$ protein in these effects. The identification of $\mathrm{N}$ protein as a pathogenicity factor provides useful insights in the possible mechanism of proteinuria in HFRS.

\section{Abbreviations}

AKl: Acute kidney injury; ANDV: Andes virus; CRP: C-reactive protein DOBV: Dobrava-Belgrade virus; dpo: Days post onset; GFP: Green fluorescent protein; HFRS: Hemorrhagic fever with renal syndrome; HREpC: Human renal epithelial cell; HRGEnC: Human renal glomerular endothelial cell; HTNV: Hantaan virus; IF: Immunofluorescence; LDH: Lactate dehydrogenase; MOI: Multiplicity of infection; PFA: Paraformaldehyde; PUUV: Puumala virus; SD: Standard deviation

\section{Acknowledgments}

We thank Christian Ackermann for his support in microscopy at the Nikon Imaging Center (Heidelberg). We thank Friedrich Frischknecht for access to Amaxa nucleofection system.

\section{Consent of publication}

Not applicable.

\section{Authors'contributions}

EK designed the study and wrote the paper. SH: performed the experiments, analyzed and interpreted the data. CN, AM made substantial contributions to acquisition and interpretation of data. JR, MZ: participated in the design of the study and helped to draft the manuscript. All authors read and approved the final manuscript.

\section{Funding}

The author received no funding for this research.

\section{Availability of data and materials}

The datasets used and analyzed during the current study are available from the corresponding author on reasonable request.

\section{Ethics approval and consent to participate}

This study was approved by the Ethics Committee of the University Hospital of Heidelberg, Germany, and it adhered to the Declaration of Helsinki. Written informed consent was obtained from the participants.

\section{Competing interests}

The authors declare that they have no competing interests.

\section{Publisher's Note}

Springer Nature remains neutral with regard to jurisdictional claims in published maps and institutional affiliations.

\section{Author details}

'Department of Nephrology, University of Heidelberg, Im Neuenheimer Feld 162, 69120 Heidelberg, Germany. ${ }^{2}$ Department of Medicine I and Clinical Chemistry/Department of Nephrology, University of Heidelberg, Heidelberg, Germany. ${ }^{3}$ Department of Internal Medicine, Rush University Medical Center, Chicago, IL, USA.

\section{Received: 26 April 2018 Accepted: 3 December 2018}

Published online: 12 December 2018

\section{References}

1. Henttonen $H$, Buchy $P$, Suputtamongkol $Y$, Jittapalapong S, Herbreteau V, Laakkonen J, et al. Recent discoveries of new hantaviruses widen their range and question their origins. Ann N Y Acad Sci. 2008;1149:84-9.

2. Ala-Houhala I, Koskinen M, Ahola T, Harmoinen A, Kouri T, Laurila K, et al. Increased glomerular permeability in patients with nephropathia epidemica caused by Puumala hantavirus. Nephrol Dial Transplant. 2002;17(2):246-52.

3. Krautkrämer E, Grouls S, Stein N, Reiser J, Zeier M. Pathogenic old world hantaviruses infect renal glomerular and tubular cells and induce disassembling of cell-to-cell contacts. J Virol. 2011;85(19):9811-23.
4. Boehlke C, Hartleben B, Huber TB, Hopfer H, Walz G, Neumann-Haefelin E. Hantavirus infection with severe proteinuria and podocyte foot-process effacement. Am J Kidney Dis. 2014;64(3):452-6.

5. Collan Y, Lahdevirta J, Jokinen EJ. Electron microscopy of Nephropathia Epidemica. Glomerular changes Virchows Arch A Pathol Anat Histol. 1978;377(2):129-44.

6. Mundel P, Reiser J. Proteinuria: an enzymatic disease of the podocyte? Kidney Int. 2010;77(7):571-80.

7. Wei C, Moller CC, Altintas MM, Li J, Schwarz K, Zacchigna S, et al. Modification of kidney barrier function by the urokinase receptor. Nat Med. 2008:14(1):55-63.

8. D'Amico G, Bazzi C. Pathophysiology of proteinuria. Kidney Int. 2003;63(3): 809-25.

9. Mantula PS, Outinen TK, Clement JPG, Huhtala HSA, Porsti IH, Vaheri A, et al. Glomerular proteinuria predicts the severity of acute kidney injury in Puumala hantavirus-induced Tubulointerstitial nephritis. Nephron. 2017:136(3):193-201

10. Saleem MA, O'Hare MJ, Reiser J, Coward RJ, Inward CD, Farren T, et al. A conditionally immortalized human podocyte cell line demonstrating nephrin and podocin expression. J Am Soc Nephrol. 2002;13(3):630-8.

11. Kraus AA, Priemer $\mathrm{C}$, Heider $\mathrm{H}$, Krüger $\mathrm{DH}$, Ulrich R. Inactivation of Hantaan virus-containing samples for subsequent investigations outside biosafety level 3 facilities. Intervirology. 2005;48(4):255-61.

12. McCloy RA, Rogers S, Caldon CE, Lorca T, Castro A, Burgess A. Partial inhibition of Cdk1 in $\mathrm{G} 2$ phase overrides the SAC and decouples mitotic events. Cell Cycle. 2014;13(9):1400-12.

13. Spiropoulou CF: Molecular Biology of Hantavirus Infection. In: Bunyaviridae. edn. Edited by Plyusnin A, Elliott RM: Caister Academic Press; 2011: 41-60.

14. Rowe RK, Pekosz A. Bidirectional virus secretion and nonciliated cell tropism following Andes virus infection of primary airway epithelial cell cultures. J Virol. 2006;80(3):1087-97.

15. Guhl S, Franke R, Schielke A, Johne R, Krüger DH, Babina $M$, et al. Infection of in vivo differentiated human mast cells with hantaviruses. J Gen Virol. 2010;91(Pt 5):1256-61

16. Raftery MJ, Kraus AA, Ulrich R, Krüger DH, Schönrich G. Hantavirus infection of dendritic cells. J Virol. 2002;76(21):10724-33.

17. Shrivastava-Ranjan P, Rollin PE, Spiropoulou CF. Andes virus disrupts the endothelial cell barrier by induction of vascular endothelial growth factor and downregulation of VE-cadherin. J Virol. 2010:84(21):11227-34

18. Gavrilovskaya IN, Gorbunova EE, Mackow NA, Mackow ER. Hantaviruses direct endothelial cell permeability by sensitizing cells to the vascular permeability factor VEGF, while angiopoietin 1 and sphingosine 1phosphate inhibit hantavirus-directed permeability. J Virol. 2008:82(12):5797-806

19. Thilo F, Liu Y, Loddenkemper C, Schuelein R, Schmidt A, Yan Z, et al. VEGF regulates TRPC6 channels in podocytes. Nephrol Dial Transplant. 2012;27(3):921-9.

20. He FF, Bao D, Su H, Wang YM, Lei $C T$, Zhang CY, et al. IL-6 increases podocyte motility via MLC-mediated focal adhesion impairment and cytoskeleton disassembly. J Cell Physiol. 2018;233(9):7173-81.

21. Connolly-Andersen AM, Thunberg T, Ahlm C. Endothelial activation and repair during hantavirus infection: association with disease outcome. Open Forum Infect Dis. 2014;1(1):ofu027.

22. Outinen TK, Tervo L, Makela S, Huttunen R, Maenpaa N, Huhtala H, et al. Plasma levels of soluble urokinase-type plasminogen activator receptor associate with the clinical severity of acute Puumala hantavirus infection. PLoS One. 2013;8(8):e71335.

23. Khaiboullina SF, Levis S, Morzunov SP, Martynova EV, Anokhin VA, Gusev $O A$, et al. Serum cytokine profiles differentiating hemorrhagic fever with renal syndrome and hantavirus pulmonary syndrome. Front Immunol. 2017:8:567.

24. Guo J, Guo X, Wang Y, Tian F, Luo W, Zou Y. Cytokine response to Hantaan virus infection in patients with hemorrhagic fever with renal syndrome. J Med Virol. 2017:89(7):1139-45

25. Vaheri A, Strandin T, Hepojoki J, Sironen T, Henttonen H, Makela S, et al. Uncovering the mysteries of hantavirus infections. Nat Rev Microbiol. 2013:11(8):539-50

26. Kirsanovs S, Klempa B, Franke R, Lee MH, Schonrich G, Rang A, et al. Genetic reassortment between high-virulent and low-virulent Dobrava-Belgrade virus strains. Virus Genes. 2010;41(3):319-28. 
27. Cimica V, Dalrymple NA, Roth E, Nasonov A, Mackow ER. An innate immunity-regulating virulence determinant is uniquely encoded by the Andes virus nucleocapsid protein. MBio. 2014;5(1):e01088-13.

28. Wang Z, Mir MA. Andes virus nucleocapsid protein interrupts protein kinase $R$ dimerization to counteract host interference in viral protein synthesis. J Virol. 2015;89(3):1628-39.

29. Gorbunova EE, Simons MJ, Gavrilovskaya IN, Mackow ER. The Andes virus Nucleocapsid protein directs basal endothelial cell permeability by activating RhoA. MBio. 2016;7(5):e01747-16.

Ready to submit your research? Choose BMC and benefit from:

- fast, convenient online submission

- thorough peer review by experienced researchers in your field

- rapid publication on acceptance

- support for research data, including large and complex data types

- gold Open Access which fosters wider collaboration and increased citations

- maximum visibility for your research: over $100 \mathrm{M}$ website views per year

At $\mathrm{BMC}$, research is always in progress.

Learn more biomedcentral.com/submissions 